Portland State University

PDXScholar

\title{
How Technology Can Affect the Demand for Bicycle Transportation: The State Of Technology and Projected Applications of Connected Bicycles
}

\author{
John MacArthur \\ Portland State University \\ Michael Harpool \\ Portland State University \\ Daniel Scheppke \\ Portland State University
}

Follow this and additional works at: https://pdxscholar.library.pdx.edu/trec_reports

Part of the Transportation Commons

Let us know how access to this document benefits you.

\section{Recommended Citation}

MacArthur, John, Michael Harpool and Daniel Scheppke. How Technology Can Affect the Demand for Bicycle Transportation: The State of Technology and Projected Applications of Connected Bicycles. NITCRR-759. Portland, OR: Transportation Research and Education Center (TREC), 2019. https://doi.org/ $10.15760 /$ trec. 237

This Report is brought to you for free and open access. It has been accepted for inclusion in TREC Final Reports by an authorized administrator of PDXScholar. Please contact us if we can make this document more accessible: pdxscholar@pdx.edu. 


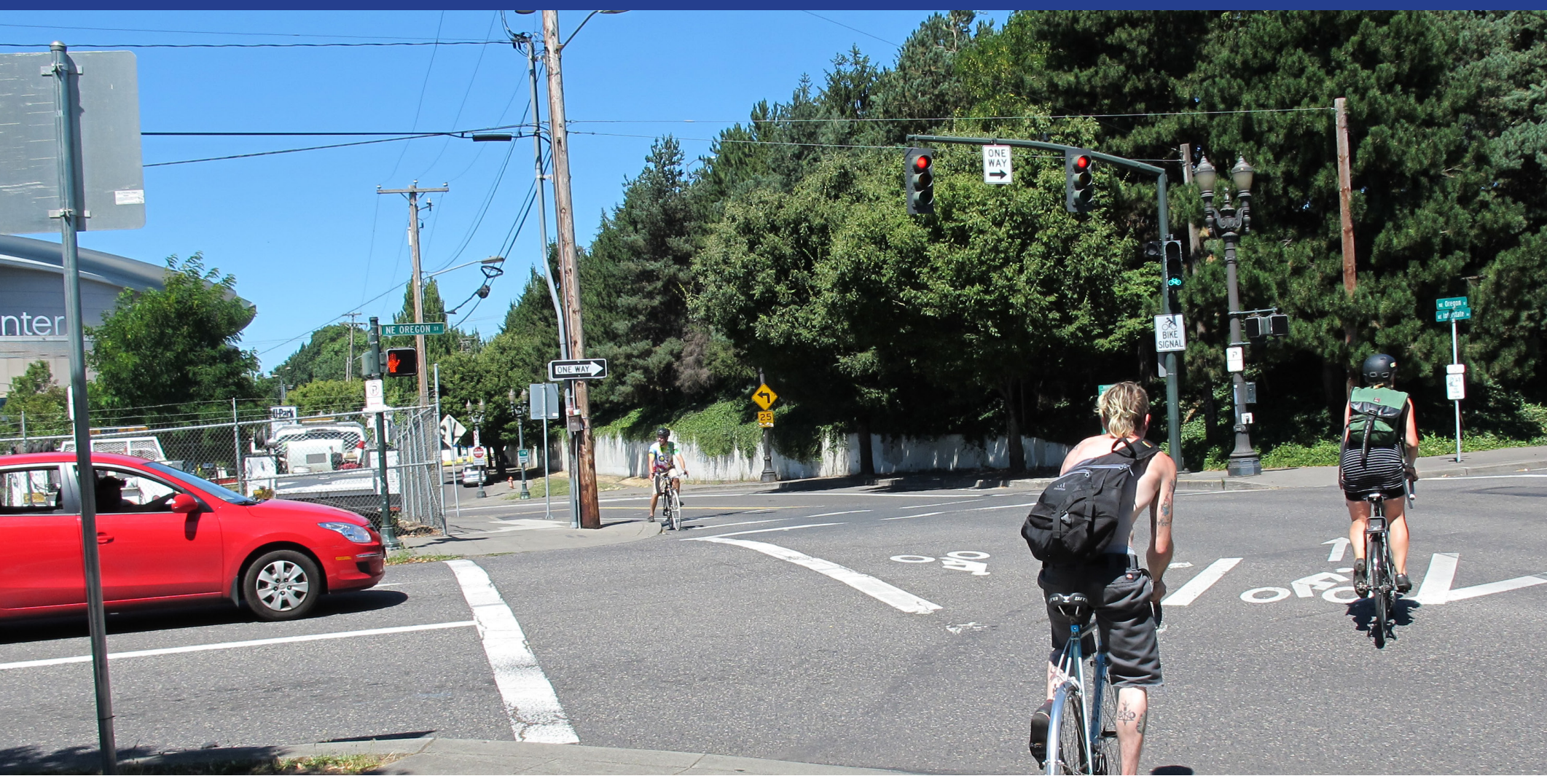

\section{How Technology Can Affect the Demand for Bicycle Transportation: The State of Technology and Projected Applications of Connected Bicycles}

John MacArthur

Michael Harpool

Daniel Scheppke

की Portland State 


\section{HOW TECHNOLOGY CAN AFFECT THE DEMAND FOR BICYCLE TRANSPORTATION}

\section{THE STATE OF TECHNOLOGY AND PROJECTED APPLICATIONS OF CONNECTED BICYCLES}

Final Report

NITC-RR-759

by

John MacArthur

Michael Harpool

Daniel Scheppke

Portland State University

for

National Institute for Transportation and Communities (NITC)

P.O. Box 751

Portland, OR 97207
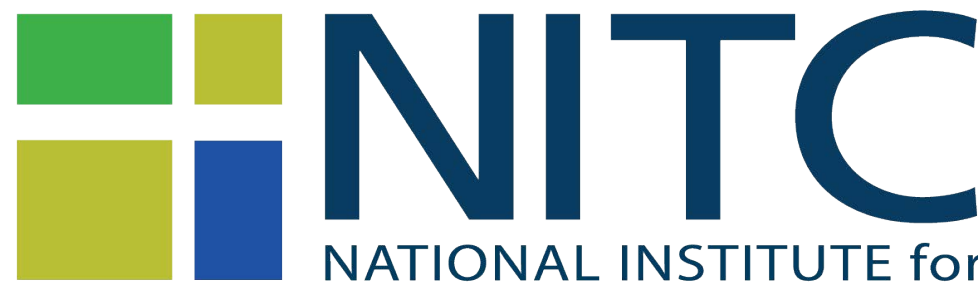

TRANSPORTATION and COMMUNITIES

September 2019 


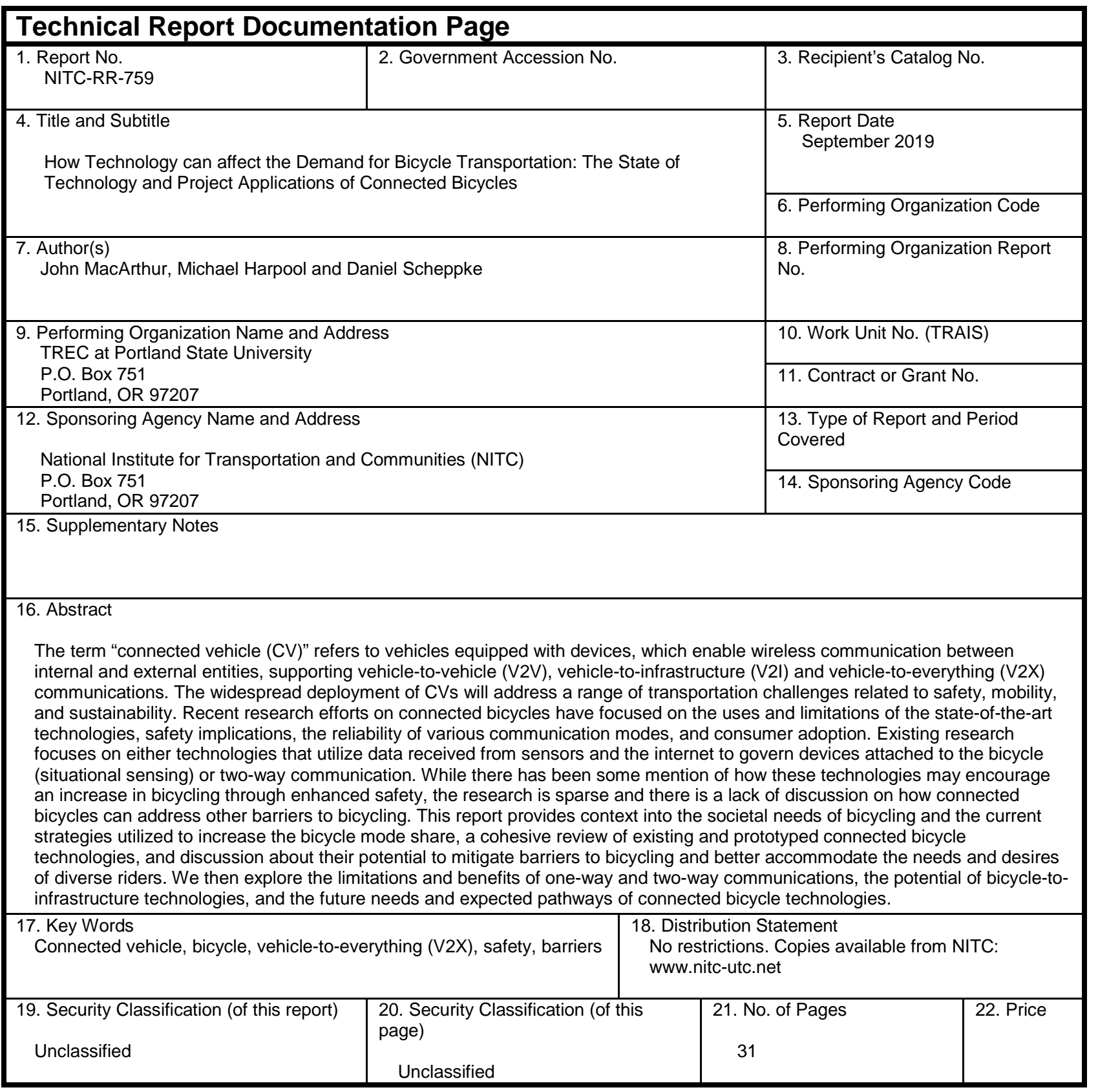




\section{ACKNOWLEDGEMENTS}

The authors would like to thank all the individuals we talked with at companies, organizations and agencies about the topic. This project was funded by the National Institute for Transportation and Communities (NITC) under grant number 759.

\section{DISCLAIMER}

The contents of this report reflect the views of the authors, who are solely responsible for the facts and the accuracy of the material and information presented herein. This document is disseminated under the sponsorship of the U.S. Department of Transportation University Transportation Centers Program in the interest of information exchange. The U.S. Government assumes no liability for the contents or use thereof. The contents do not necessarily reflect the official views of the U.S. Government. This report does not constitute a standard, specification, or regulation.

\section{RECOMMENDED CITATION}

MacArthur, John, Michael Harpool and Daniel Scheppke. How Technology Can Affect the Demand for Bicycle Transportation: The State of Technology and Projected Applications of Connected Bicycles. NITC-RR-759. Portland, OR: Transportation Research and Education Center (TREC), 2019. 


\section{TABLE OF CONTENTS}

EXECUTIVE SUMMARY

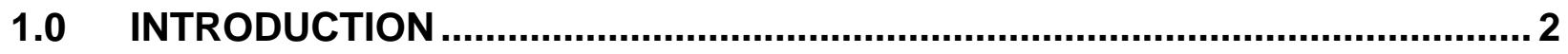

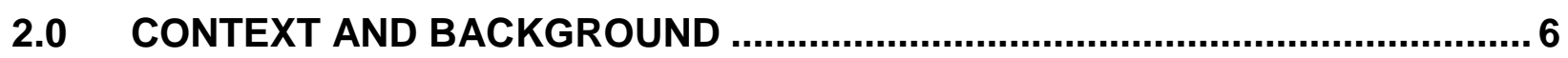

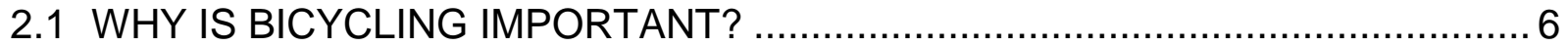

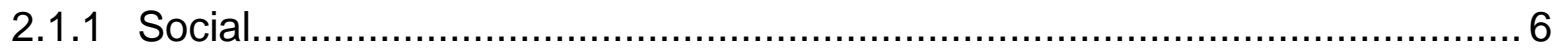

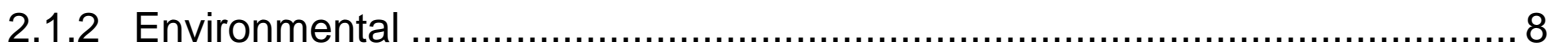

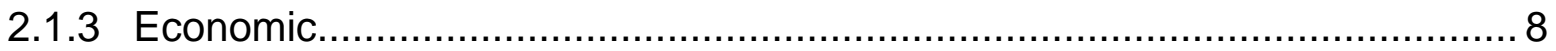

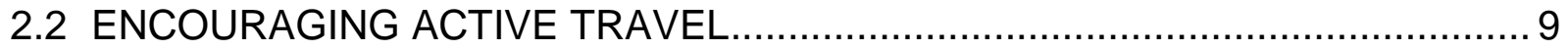

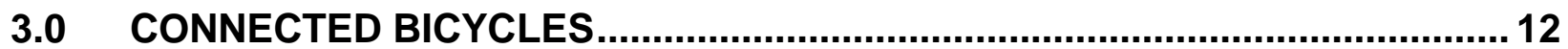

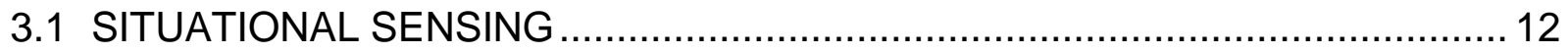

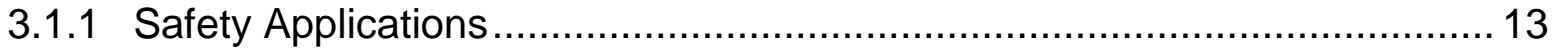

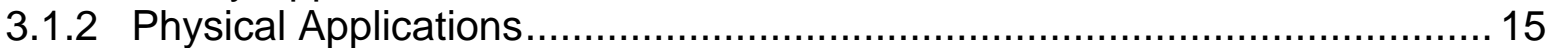

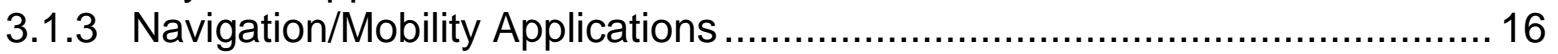

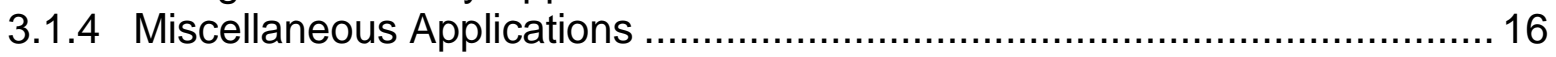

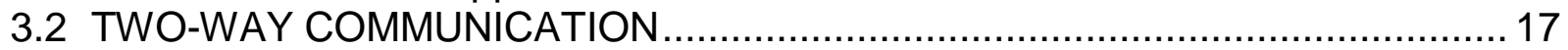

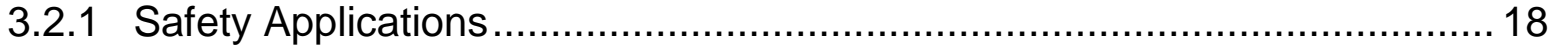

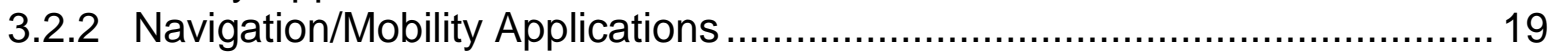

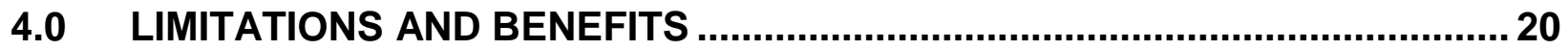

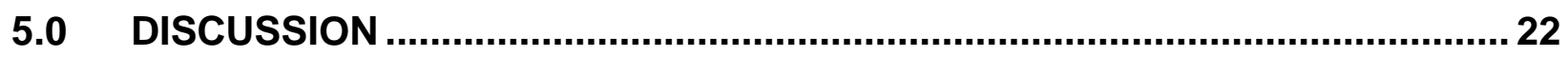

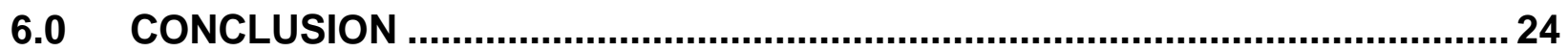

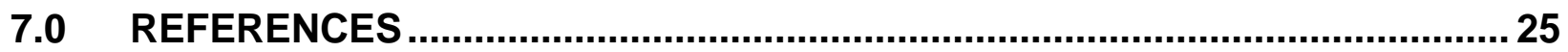

\section{LIST OF TABLES}

Table 1 - Barriers to Cycling and Connected Applications ........................................ 14

\section{LIST OF FIGURES}

Figure 1 - CV Environment (Source: NYCDOT) …................................................. 3

Figure 2 - U.S. DOT Connected Vehicle Applications ............................................ 4

Figure 3 - Most Common Bicycle Crash Types (SDOT, 2017) ................................. 7

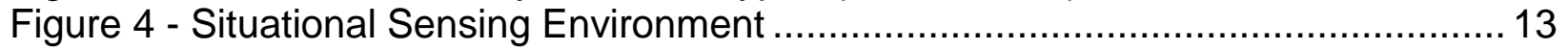

Figure 5 - Two-Way Communication Environment .................................................... 18 


\section{EXECUTIVE SUMMARY}

As the societal benefits of active travel come to fruition in the U.S., cities seek to encourage bicycling by addressing the specific barriers and needs of the mode's diverse users. Advocates, academics, and practitioners often focus on the impacts of infrastructure, policies and programs, and access, yet technology tends to be ignored as a critical component of increasing bicycling rates.

The term "connected vehicle (CV)" refers to vehicles equipped with devices, which enable wireless communication between internal and external entities, supporting vehicle-to-vehicle (V2V), vehicle-to-infrastructure (V2I) and vehicle-to-everything (V2X) communications. The widespread deployment of $\mathrm{CVs}$ will address a range of transportation challenges related to safety, mobility, and sustainability. Recent research efforts on connected bicycles have focused on the uses and limitations of the state-ofthe-art technologies, safety implications, the reliability of various communication modes, and consumer adoption. Existing research focuses on either technologies that utilize data received from sensors and the internet to govern devices attached to the bicycle (situational sensing) or two-way communication. While there has been some mention of how these technologies may encourage an increase in bicycling through enhanced safety, the research is sparse and there is a lack of discussion on how connected bicycles can address other barriers to bicycling.

This report provides context into the societal needs of bicycling and the current strategies utilized to increase the bicycle mode share, a cohesive review of existing and prototyped connected bicycle technologies, and discussion of their potential to mitigate barriers to bicycling and better accommodate the needs and desires of diverse riders. We examined the existing and projected applications of connected bicycle technologies and explored the ways in which they could address some of the barriers to bicycling. The information in the report links barriers to cycling to the appropriate CV applications and considers the communication type and sensor technology, which provides a framework for future development and discussion around connected bicycles.

In conducting this research, it has become evident that there is a lack of consideration of bicyclists in the U.S. DOT, state DOTs', and local DOTs' CV initiatives, but also in city bicycle planning and Vision Zero. The U.S. DOT has spent many years developing more than three dozen CV applications, yet none of them directly acknowledge the presence of bicyclists on the road. In these applications bicyclists take the same role as pedestrians in that their presence is recognized by pedestrian detection technologies. We believe that bicycle manufacturing companies, bicycle advocates, and active transportation planners should be included in the connected-vehicle conversations taking place at all scales of government. As connected technologies advance these groups have a unique opportunity to explore new concepts and encourage the integration of connected bicycles. 


\subsection{INTRODUCTION}

Over the past two decades, federal, state, and local governments in the United States have expressed a growing interest in supporting the needs and desires of individuals who chose to travel by bicycle. Concerns for public health and well-being, environmental degradation, and community livability have led to policies, programs, and infrastructural investments meant to enhance the opportunities and conditions for active transport. The primary goal of these efforts is to encourage a modal shift from singleoccupancy vehicles. However, numerous barriers continue to deter the use of bicycles over other modes and limit our cities' capacity to realize the full potential of bicycle transportation.

The concern for safety reigns as one of the most significant deterrents, and in many neighborhoods in the U.S. these concerns are valid; the National Highway Safety Traffic Administration (NHSTA) reported that in 2015 there were 818 bicyclist fatalities and 45,000 injuries (U.S. DOT, 2017a). Recent research suggests that bicycling rates would increase with improved separation and safety from automobile traffic (Sallis et al., 2013; Winters et al., 2011; Dill and McNeil, 2016; Buehler and Dill, 2016; Furth, 2012). Individuals are also deterred from bicycling by physical and environmental barriers (i.e., health, topography, and distance); unsatisfactory routes and navigation; bicycle security and maintenance concerns; the need to transport cargo and children; and other unmet needs. The city of Portland, already arguably one of the best large U.S. cities for bicycling, adopted in 2010 the Portland Bicycle Plan that aims to achieve a 25\% mode share by 2030 . Yet even with its cutting-edge bike infrastructure, land use planning, and progressive programs, Portland's 2011 bicycle commute mode share was $6.3 \%$, according to the U.S. Census. Comparatively, the nationwide bike commute mode share is under $1 \%$ (LAB, 2016). These numbers indicate that there are social and physical barriers to bicycling that are not currently being addressed. Although these barriers have deterred the growth of cycling in the U.S., recent advancements in connected vehicle (CV) and bicycle technologies have the capacity to minimize these barriers and increase cycling.

The concept of CVs is not new; research efforts to gauge the reliability and practicality of CV technologies date back to the 1990s. The term "connected vehicle" refers to vehicles equipped with devices, which enable wireless communication between internal and external entities, supporting vehicle-to-vehicle (V2V), vehicle-to-infrastructure (V2I) and vehicle-to-everything (V2X) communications (Lu et al., 2014) (Figure 1). CV technologies will support and enhance the benefits currently provided by vehiclemounted detection and communication systems. Recent advancements in sensor technology have enabled manufacturers such as Jaguar Land Rover and Volvo to develop systems that can detect bicyclists, pedestrians, and other vehicles to help prevent crashes. The widespread deployment of CVs will address a myriad of transportation challenges related to safety, mobility, and sustainability. 


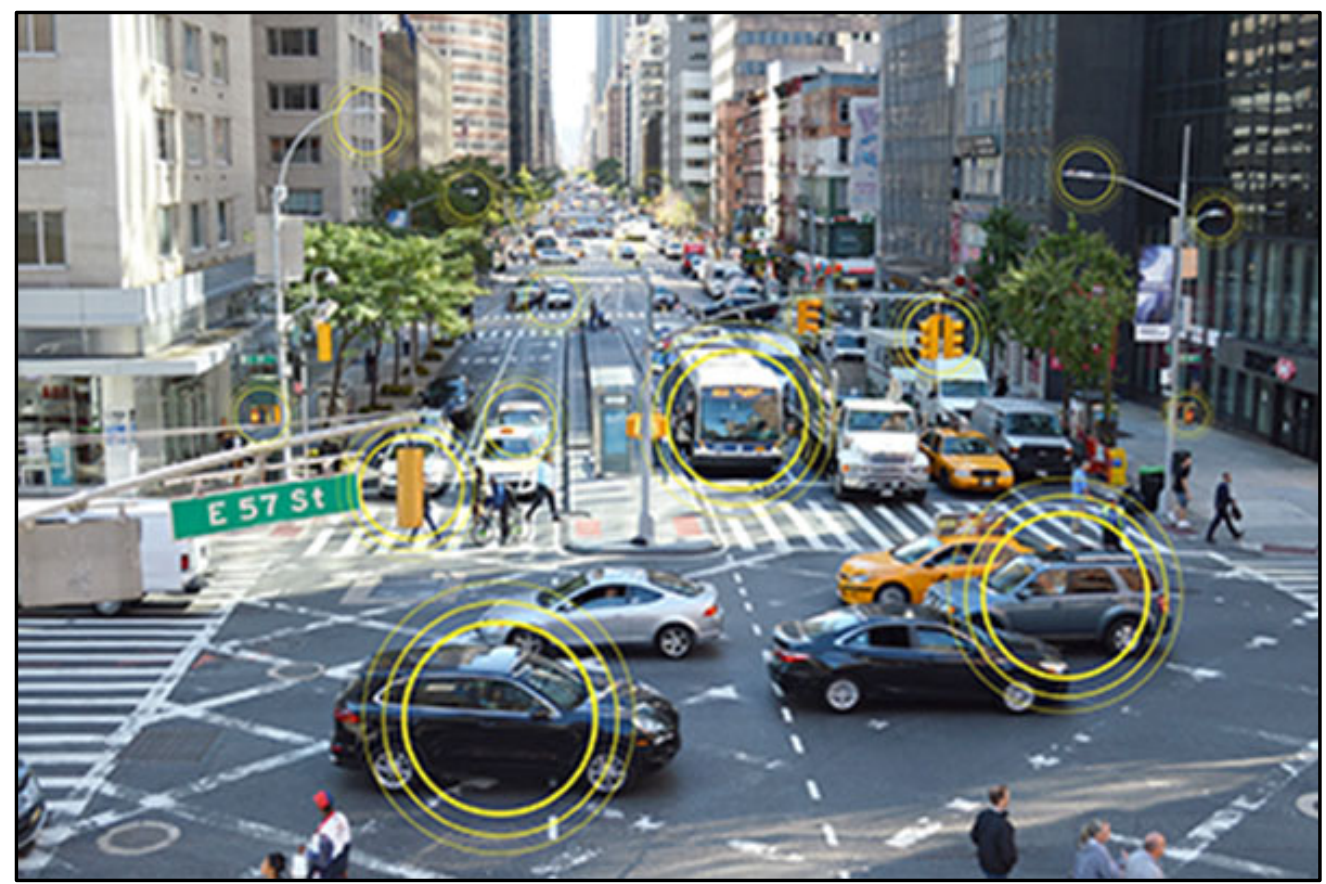

Figure 1 - CV Environment (Source: NYCDOT)

Federal endorsement of CV technology came in 2016 when the U.S. Department of Transportation proposed a mandate that would add V2V technology to all new light-duty vehicles. Since the early 2010s, CV application prototyping and assessment has been central to the U.S. Department of Transportation's CV research and development activities (U.S. DOT, 2018a). These efforts have led to the development of more than three dozen CV applications (Figure 2). These applications are essentially capabilities of $\mathrm{CV}$ technologies through V2V, V2I, and V2X communications. The technology has the potential to reduce unimpaired vehicle crashes by $80 \%$ (U.S. DOT, 2017c). As shown in Figure 2, the CV program is very focused on in-vehicle systems and only a few of these applications focus on pedestrians, and none of the applications make explicit mention of bicyclists; however, many of the safety and mobility CV applications could benefit bicyclists. For the applications outside in-vehicle systems and advanced warning systems, the handheld devices are the focus for technology development, especially at signalized intersections. The Mobile Accessible Pedestrian Signal System (PED-SIG) is an application that facilitates automated calls from a smartphone to a traffic signal for crossing requests (U.S. DOT, 2017d).

From the outset, dedicated short-range communication (DSRC)/IEEE 802.11p devices have been the favored technology to satisfy V2V and V2I communications and are still considered the technology standard; however, cellular companies and associated 5G supporters have begun to push against any mandate, suggesting a market-driven solution of 3GPP-defined C-V2X (3rd Generation Partnership Project cellular V2X) technology. These advocates claim that by the time DSRC is able to make any significant difference in safety, 5G cellular networks will be able to provide all of the same benefits with more coverage, reliability and cheaper cost (Calem, 2017; 5 G American, 2017). In 2016, the U.S. DOT launched the Connected Vehicle Pilot 
Program, awarding cooperative agreements to Tampa (FL), New York City (NY), and Wyoming to initiate the deployment, testing, and operationalization of CV technology. In terms of the safety benefits of DSRCs, the NHSTA estimates that CV technologies have the potential to reduce up to $80 \%$ of crashes where drivers are not impaired (U.S. DOT, 2018b).

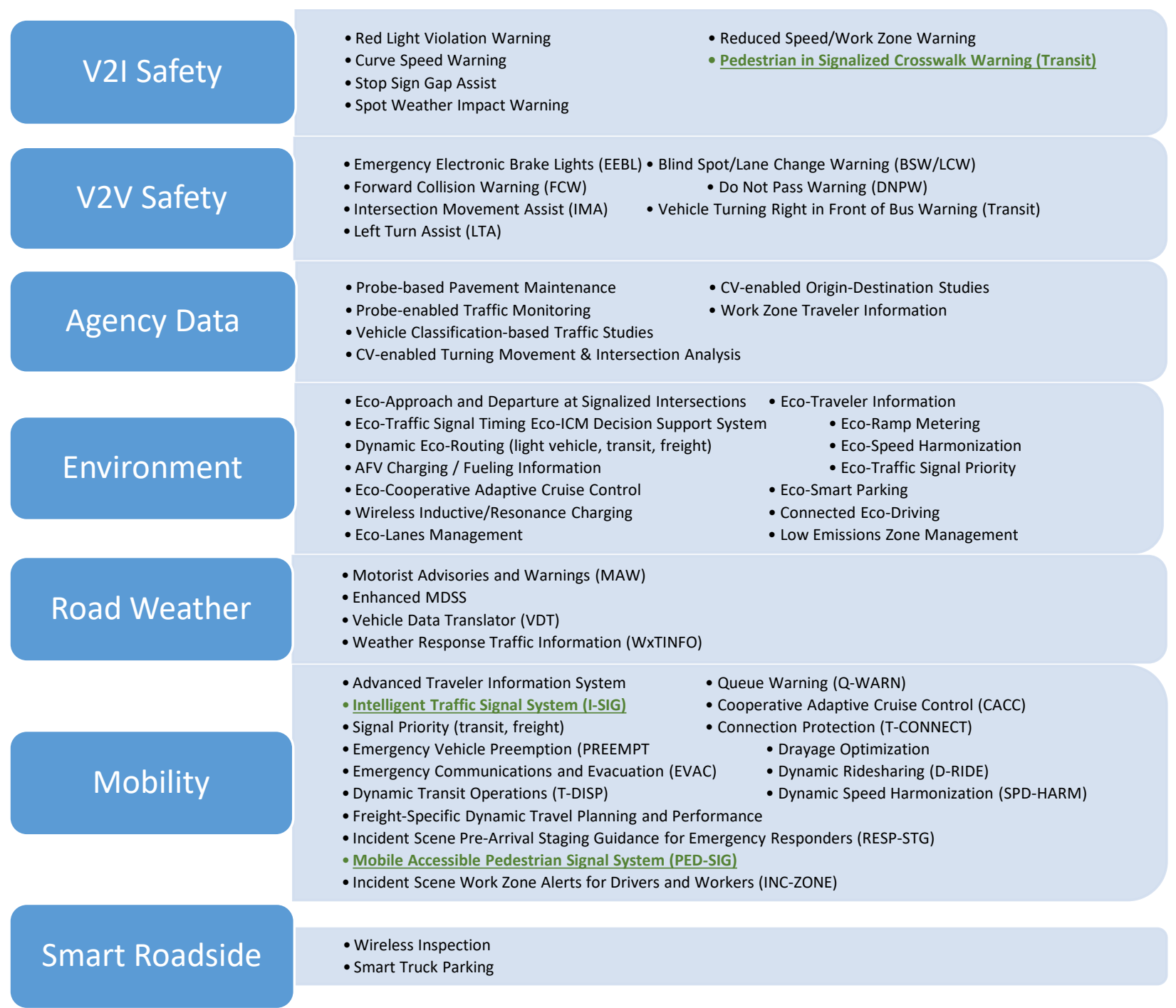

Figure 2 - U.S. DOT Connected Vehicle Applications

The notion of connected bicycles emerged in the early 2010s through two distinct yet interconnected conceptualizations. The first focuses on one-way communication using sensors and modules which collect and transmit data directly to the bicyclist through the internet and other integrated devices. The technology that captures this information can be built-in (smart bike/e-bike) or brought-in (handlebars, helmets, bicycle computers, locks, etc.), and they tend to rely on integration with smartphone technology (Piramuthu, 2016). The use of smartphones by bicyclists was spurred by the rise of wayfinding apps and sport tracking apps such as Strava; these apps continue to be a critical component 
of many connected bicycle technologies. The second is conceived as the integration of bicycles into the $\mathrm{V} 2 \mathrm{X}$ communication environment. This concept relies on direct twoway communications between bicycles and vehicles (B2V) and infrastructure (B2I). Technologies for both concepts continue to be explored today with a common goal of enhancing the experiences and safety of the bicyclist (Piramuthu, 2017; Silla et al., 2017; Tome, 2018).

Recent research efforts on connected bicycles have focused on the uses and limitations of the state-of-the-art technologies (Piramuthu, 2016; Piramuthu, 2017); safety implications (Razzaque and Clarke, 2015; Silla et al., 2017); the reliability of various communication modes (Jenkins et al., 2016; Anaya et al., 20149); and consumer adoption (Piramuthu, 2017; Silla et al., 2017). While there has been some mention of how these technologies may encourage an increase in bicycling through enhanced safety, the research is sparse and there is an absence of discussion on how connected bicycles can address other barriers to bicycling. Furthermore, existing research seems to focus on either technologies, which utilize data received from sensors and the internet to govern devices attached to the bicycle (situational sensing) or two-way communication. We believe that it is important to consider the two side by side to assess the existing conditions and future trends of the state of technology. This report will provide context into the societal needs of bicycling and the current strategies utilized to increase the bicycle mode share; a cohesive review of existing and prototyped connected bicycle technologies; and discussion of their potential to mitigate barriers to bicycling and better accommodate the needs and desires of diverse riders. Finally, we will explore the limitations and benefits of one-way and two-way communication, the potential of bicycle-to-infrastructure (B2I) technologies, and the future needs and expected pathways of connected bicycle technologies. 


\subsection{CONTEXT AND BACKGROUND}

\subsection{WHY IS BICYCLING IMPORTANT?}

\subsubsection{Social}

Auto-dependent land use practices in the decades following World War II have led to numerous social issues within U.S. cities. Investments into the transportation system during those years were supported by the assumption that individuals would rely on a motor vehicle for the vast majority of trips. The resulting projects created physical barriers which divided neighborhoods, exposed individuals to excess noise and air pollution, and created dangerous and unpleasant living conditions (Golub et al., 2013; Litman, 2017). These social costs have had a disproportionate impact on lower-income and minority households and individuals who cannot or should not operate a motor vehicle due to age, income, and health (20-40\% in most communities; Litman, 2017). Along with other factors, prioritizing the mobility needs of vehicle owners over those who are dependent on active modes has led to high rates of pedestrian and bicyclist traffic fatalities and sedentary lifestyles.

In recent years, traffic safety for non-motorized users has become a significant public health issue and prioritized concern in U.S. cities. In 2015, there were 5,376 pedestrian (87\%) and 818 bicyclist (13\%) fatalities and 115,000 injuries (61\% and 39\%, respectively) in the U.S. alone (U.S. DOT, 2017a; U.S. DOT, 2017b). People of color have been disproportionately affected by these collisions; in 2006, pedestrian and bicyclist fatality rates for African Americans and Hispanics were nearly two times higher than the rate for Whites, and the rate for American Indian/Alaska Native Americans was more than four times higher (NHTSA, 2009). A study by the Federal Highway Administration (FHWA) found that over $18 \%$ of vehicle-bicycle collisions resulted in serious and fatal injuries to the bicyclist (Hunter et al., 1996). In this study, the FHWA separated all collisions into three categories, parallel-path events (36\%), crossing-path events (57\%), and specific circumstances (7\%). Of the parallel-path events, the most common crash types included motorist turn/merge into bicyclist's path $(12.2 \%)$, motorists overtaking the bicyclist (8.6\%), and bicyclist turn/merge into motorist's path. For crossing-path events, the most common crash types were motorist failed to yield to bicyclist (21.7\%), bicyclist failed to yield at an intersection (16.8\%), and bicyclist failed to yield midblock (11.8\%). These six crash types accounted for the vast majority of all vehicle-bicyclist collisions (Hunter et al., 1996). Seattle DOT determined 57\% of bicycle crashes occur at intersections, $5 \%$ are caused by dooring and the top three bicycle crash types are from left hooks, angle and right hooks (See Figure 3) (SDOT, 2016). Schneider and Stefanich found that bicycle crashes were significantly more likely to be fatal when motorists overtook and struck a bicyclist from behind, often in low-light conditions and in high-speed areas (2016). 
BPSA - MOST COMMON BICYCLE CRASH TYPES
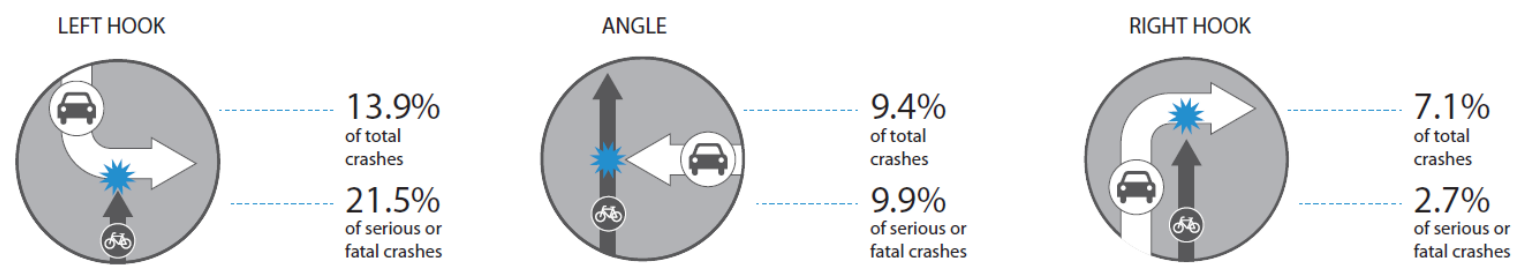

Figure 3 - Most Common Bicycle Crash Types (SDOT, 2016)

These crash statistics are indicative of the social need to enhance the safety margins for bicyclists. Increased efforts to improve the infrastructural conditions (i.e. more bike lanes) for bicyclist and pedestrians and provide supportive educational programs and traffic regulations have shown to have a positive effect on safety for non-motorized users (Pucher and Buehler, 2010). Unlike motor vehicles, bicycles pose minimal risk to other road users. Thus, encouraging more individuals to travel by bicycle could generate safer environments, which could ultimately attract more users and create safety in numbers; Marshall and Garrick (2011) found that cities with higher bicycling rates tend to have a much lower risk of fatal crashes for all road users when compared to cities with lower bicycling rates.

Physical inactivity can increase an individual's chances of obesity, cardiovascular disease, diabetes, high blood pressure, depression, and other chronic diseases; it is estimated that inactive lifestyles are responsible for 200,000 deaths per year in the U.S., and more than $70 \%$ of U.S. citizens do not meet recommendations for physical activity (Frank, 2000). The links between physical activity, public health, and active transportation have been well documented. Sallis et al. (2004) claim that active transportation has the capacity to contribute significantly to overall levels of physical activity and that even small increases in physical activity can improve public health. Pucher et al. (2010b) found significant inverse relationships between active travel and obesity utilizing data from 14 countries, all 50 U.S. states, and 47 of the 50 largest U.S. cities.

In a review of the literature, Pucher and Buehler (2010) reveal that active transportation is directly related to improved health in older adults, decreased mortality rates, and improved resting blood pressure. Their findings suggest that bicycling and walking to work can be one of the most practical and effective ways to meet recommended physical activity levels. Traveling by bicycle can also benefit individuals' mental health; Smith (2016) found that those who walk and bike to work tend to be happier with their commutes than those who drive or utilize some other mode. Furthermore, Rogers et al. (2011) provided evidence that levels of social capital are higher in neighborhoods that support active travel than those which do not. Strong social networks, personal connections, and other aspects of social capital are an important component of quality of life and can benefit both communities' and individuals' social well-being. 


\subsubsection{Environmental}

Since 1980, the number of vehicle miles traveled (VMT) each year has increased dramatically and has grown three times faster than the U.S. population (Ewing et al., 2007). Rapid growth in VMT has led to alarming rates of greenhouse gas emissions (GHG), especially carbon dioxide (CO2); the transportation sector is the largest source of GHG emissions, accounting for $28.5 \%$ of the national total (U.S. EPA, 2018). Studies have shown that even with technological improvements for fuel efficiency, CO2 emissions will continue to rise without a significant decrease in VMT (Ewing et al., 2007).

In this light, bicycles and other alternatives to gas-powered vehicles have become an increasingly attractive solution. Increasing the proportion of people who travel by bicycle can dramatically decrease VMT and the levels of harmful pollutants emitted into the environment. Some of the pollutants produced by the combustion of gas have detrimental local impacts (carbon monoxide and particulates), while others have regional and global impacts (i.e., methane and CO2) (Litman, 2017). A shift towards active modes for short urban trips can result in a significant reduction in emissions, because per mile emissions tend to be greatest for these trips due to cold starts and congestion (Litman, 2017). Furthermore, increasing rates of active transportation could decrease the demand for vehicle production, which is responsible for considerable amounts of energy consumption and pollution. Finally, decreasing the amount of impervious surface for new roads can have a significant impact on the local environment by reducing the urban heat island effect, reducing damage caused to rivers and riparian zones through improved storm water management, and reducing the transport of pollutants into the hydrological system.

\subsubsection{Economic}

Auto-dependent design and general reliance on motor vehicles have also generated numerous economic burdens. A recent study estimated that in 2017 traffic congestion costed U.S. drivers more than $\$ 305$ billion in direct (wasted time and fuel) and indirect expenditures (increased freight delivery time); as the demand for driving continues to surpass the supply of roadway it is expected that congestion costs will increase (Cookson, 2018). Furthermore, local, state, and federal governments spend billions of dollars per year on highway expansion, repair, and operations ( $\$ 164.5$ billion in 2014), and there is still an $\$ 836$ billion backlog of capital improvement work that requires funding (ASCE, 2018). With the average U.S. household spending $\$ 8,755$ on transportation in 2016, it is the second-largest household expenditure category (U.S. DOT, 2017c). Citizens who rely on active modes require access to the same sort of destinations (i.e., work, education, shopping centers, etc.) as those who rely on personal vehicles; thus, neglecting their needs can have a negative impact on local economic activity and individual economic opportunity. Modal shifts from driving to bicycling could help mitigate the impact of these economic burdens on the government, households, and individuals. 
A study on the employment impacts of surface infrastructure projects by Garret-Peltier (2011) found that the construction of bicycle and pedestrian infrastructure generates between 9 and 11.4 local jobs per one million dollars spent, compared to an average of 7.8 jobs for road-only infrastructure. Garret-Peltier argues that the direct and indirect benefits of non-motorized infrastructure projects are substantial and should be prioritized over automobile-only projects. Studies have also shown that increasing rates of active transportation can significantly reduce the costs of congestion, road maintenance, parking facilities, health care, and motor vehicle accidents (Litman, 2017). Furthermore, shifting from driving to bicycling can reduce overall costs for commuters (i.e., vehicle and fuel expenditures), which can have a positive effect on regional economic activity by increasing household budgets for consumption.

Active transportation networks connect non-motorist consumers to restaurants, retailers, recreational facilities, and other establishments that they may otherwise never visit, due to a gap in the transportation system. Thus, constructing these networks and filling this gap can enhance local consumption as well as provide alternative employment options to individuals without access to a motor vehicle. Clifton et al. (2012) found that nonmotorists tend to be competitive consumers in comparison to their counterparts; citizens who arrived at shopping destinations on bike or foot, on average, spend similar amounts or more than those who arrived by automobile. Their results also suggest that nonmotorists tend to be more frequent patrons, making more trips to local establishments. In addition to enhancing general retail consumption patterns, active transportation also serves to benefit particular industries such as bike shops, livability-oriented real estate development, and tourism (Litman, 2017).

As the research discussed in this section indicates, increasing levels of active transportation can enhance the safety and livability of communities. It has also introduced some of the fundamental barriers to bicycling (i.e., safety, access, perceptions, and connectivity), which must be addressed to realize significant growth in utilitarian bicycling. The following section will discuss the strategies currently being utilized to address those barriers.

\subsection{ENCOURAGING ACTIVE TRAVEL}

A growing body of research shows that an increase in active transport can be achieved through infrastructural improvements, enhanced access to facilities, supportive policies, advocacy, and outreach and promotion programs (Pucher et al., 2010a; Savan et al., 2017; VTPI, 2017; Dill et al., 2013; Handy et al., 2014). Correspondingly, growth in the public presence of bicycling can encourage even higher rates of bicycling. Technology is another component with the capacity to encourage more bicycling, yet it is often overlooked by active transportation professionals, city planners and advocacy groups. This section will acknowledge the positive impacts of recent efforts to encourage bicycling and then discuss the role of bicycle manufacturers and technology.

We reviewed 25 regional and city bicycle plans and eight Vision Zero plans. In general, the plans make little to no reference to connected technologies as a component of city 
bicycle planning. Twenty of the bicycle plans and eight of the Vision Zero plans discuss the importance of signalized intersections, signal prioritization and actuated bicycle detection devices. Most of the sensors mentioned where for bicycle detection to count or activate signals, such as passive infrared, infrared, microwave, video and inductive loops. Only three plans mention e-bikes as a device that needs to be considered for use and addressed in future planning. This summary analysis shows that bicycling planning is not keeping pace with technology advancements. One possible reason for the lack of technology being included in these plans is that only five plans where developed after 2015, though the Vision Zero plans are more current.

As with other modes, the propensity to travel by bicycle is dependent on the cohesiveness, functionality, safety, and accessibility of the transportation network. Investment in active transportation infrastructure has increased dramatically in recent years, and there is considerable evidence that these investments can lead to significant increases in active travel. Numerous studies demonstrate a positive correlation between the quantity of bicycle infrastructure within cities and rates of bicycle transportation (Lyons et al., 2014; Dill and Carr, 2003; Buehler and Pucher, 2012). At the household level, Moudon et al. (2005) found that closer proximity to bicycle infrastructure is associated with more frequent bicycle use; in their study of the urbanized King County area, households closer to separated bicycle infrastructure had higher rates of bicycling than those further away. In North America, the real and perceived risk imposed by motor vehicles is the primary reason individuals do not ride more frequently (Furth, 2012); these studies show that providing designated spaces for bicyclists (i.e., bike lanes and separated paths) can reduce that risk and increase the attractiveness of bicycling for demographics other than those who are comfortable riding in traffic. Furthermore, they suggest that these networks must be easily and safely accessible or their use will remain limited (Dill and Carr, 2003; Moudon et al., 2005).

Scholars have also studied how different policies and programs may impact levels of active transportation. Programs that incite critical mass, such as Bike-to-Work Day/Months and Ciclovias or Open Streets, are often limited in duration, yet they tend to encourage active travel beyond their short-term time frame (Pucher et al., 2010a; Rose and Marfurt, 2007). Safe Routes to School and similar programs try to encourage active travel amongst children; Boarnet et al. (2005) found that funding from California's Safe Routes to School legislation resulted in increased levels of children walking and bicycling to school. Individualized marketing strategies have been successfully implemented as a low-cost method to promote walking, bicycling, transit, and other forms of environmentally friendly transportation. A longitudinal evaluation of In Motion, King County Metro Transit's community-based social marketing approach, revealed that the program resulted in a significant shift from driving alone to active travel and transit (Cooper, 2007).

In the U.S., bike share programs are becoming an increasingly popular way to address some of the transportation challenges within cities. Bike share programs can enhance access to active transportation by limiting the need to own and care for a bicycle. They also serve as an important connection to public transit, acting as a viable first- and last- 
mile transportation option. Aside from promotional programs, it is essential for municipalities to provide support for bicycling through local and regional plans. Aytur et al. (2008) found that counties that included non-automobile transportation improvements and a comprehensive set of policies to guide development in their land use plans had higher levels of transportation- and leisure-oriented physical activity. Municipalities should expect an increase in the presence of bicycling to serve as a catalyst to even more bicycle travel; Dill and Voros (2007) found that individuals with coworkers who ride a bicycle to work, and those who frequently see others bicycling, tend to ride more frequently than those who do not.

The strategies mentioned above seek to address the barriers to bicycling as well as the fundamental mobility needs of bicyclists. Advancements in bicycle technology could contribute significantly to this challenge; yet, technology has surprisingly received little attention from scholars and practitioners in this field. The studies that do exist have looked at the role of developments in bicycle equipment and electric assist. Lovejoy and Handy (2012) argue that developments in bicycle components (e.g., frame, brakes, and electric assist) and gear (e.g., lights, helmets, and trailers) can help improve the bicycling experience (e.g., safety, reliability, and the need to carry cargo). This is critical because individuals with various transportation options will be more apt to choose bicycling if the experience is competitive with other modes. In a study of e-bike use in North America, MacArthur et al. (2018) found that electric assist technologies can encourage greater rates of bicycling. Respondents in this study reported that e-bikes had encouraged them to ride more often and ride for longer trips not necessarily feasible on a standard bicycle. Furthermore, e-bikes attracted individuals who previously did not ride a bicycle or had health conditions which limited their ability to ride a standard bicycle. Similarly, a study in Portland found that e-bikes facilitate travel to more distant locations, more frequent riding, and participation amongst a wider range of users by reducing the impact of certain barriers such as hills and heavy perspiration (MacArthur et al., 2017).

These studies demonstrate how developments made by bicycle and bicycle accessory manufacturers can address some of the unmet needs and desires of utilitarian bicyclists; however, a similar study has not yet been conducted on the recent advancements in connected bicycle and V2X technologies. It is our contention that the proper promotion and integration of these technologies could significantly increase the bicycle mode share and foster safe and livable communities. In the following section we will discuss the applications of these technologies and the specific barriers and needs they can address. 


\subsection{CONNECTED BICYCLES}

Although the U.S. DOT CV applications mentioned in Figure 2 focus primarily on V2V and V2I communication, they can be useful for thinking about how new technologies could improve conditions for non-motorized road users in the future. After reviewing each of the applications, we identified those that could potentially benefit bicyclists. These applications are listed in Table 1 along with a list of additional applications not considered by the U.S. DOT. These were developed through an extensive scan of connected bicycle technologies to acknowledge connected bicycle applications currently available to bicyclists. Table 1 also cites the specific barriers addressed by each application, whether the application could be supported by two-way communication modes, and whether they rely on sensor information. Below we will explore the relevant applications of situational sensing technologies and of two-way communications, focusing on how they can facilitate a better and safer bicycling experience.

\subsection{SITUATIONAL SENSING}

Situational sensing encompasses a myriad of technologies that have been developed to enhance the bicycling experience. Many of these technologies are equipped with sensors and modules (e.g., accelerometers, gyroscopes, GPS chips, light and motion sensors, etc.) which collect data that can be shared on the web and with the bicyclist through a smartphone and/or other integrated devices, which can make use of the information. The type of data gathered by these devices can be categorized into four groups: trip information (e.g., route, speed and distance); bicyclist information (e.g., heart rate, blood pressure, and endurance); bicycle status information (e.g., tire pressure and battery life); and environmental information (e.g., potholes, weather, topography, and traffic). However, not all of the situational sensing devices utilize sensor technology. Some devices connect to compatible smartphones and utilize data from the internet (e.g., navigation devices) and others communicate directly with compatible local devices for less complex tasks (e.g., hands-free calling and turn signal activation). Bicycle manufacturers and technology companies have developed both brought-in (smart locks, bicycle computers, mounted taillights and headlights, etc.) and built-in (instrumented bicycles and e-bikes) situational sensing products. Advancements in connected wearables, especially helmets, also play an important role in the connected bicycle system, because they provide a platform to transmit audible and visual alerts to the bicyclists as well as surrounding road users. Although many of these devices transmit and make use of real-time information, they are not in direct and continuous communication with surrounding entities or other road users. Figure 4 depicts a situational sensing environment. In this section, we will introduce the state-ofthe-art connected bicycle technologies and the applications they support which address barriers faced by bicyclists. Safety applications, physical applications, navigation and mobility applications, and miscellaneous applications (e.g., cargo and bicycle security) will each be discussed in turn. 


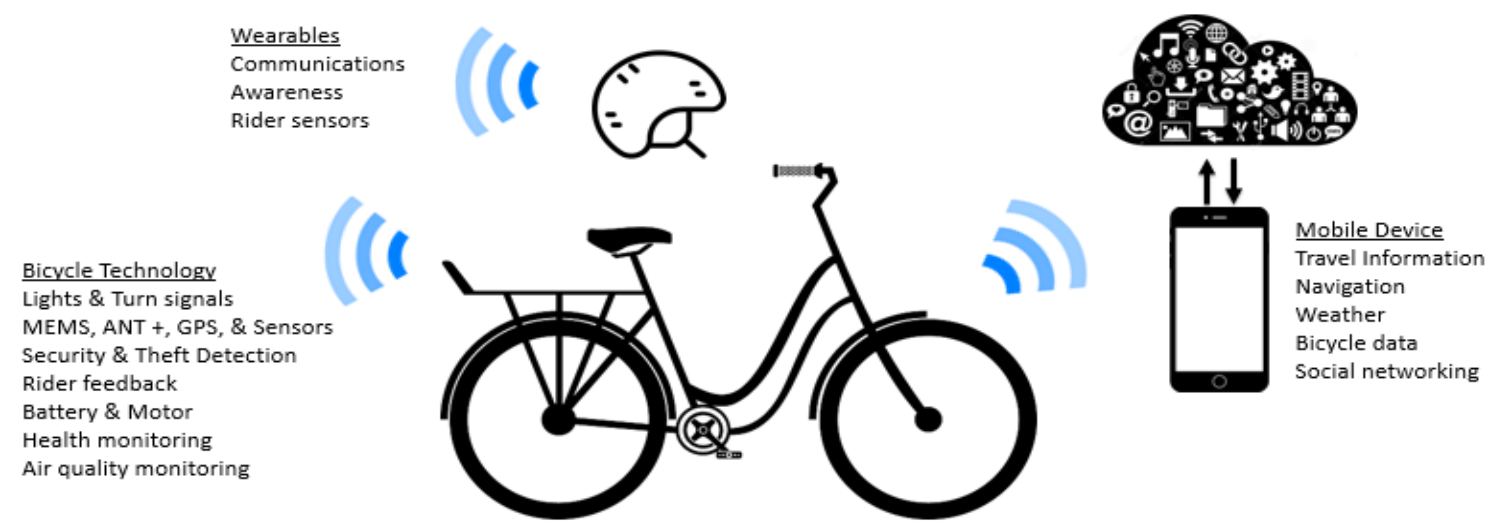

Figure 4 - Situational Sensing Environment

\subsubsection{Safety Applications}

Several connected bicycle technologies can detect and alert bicyclists of approaching vehicles. These devices most commonly come in the form of a mounted taillight. The Garmin Varia accomplishes the task by using an integrated radar, which reports the approximate distance of approaching vehicles to a handlebar-mounted display. The Hexagon taillight contains a HD camera, which allows the bicyclist to stream live videos through their smartphone. See.Sense ICON utilizes sensor technology to identify risky situations, such as an encroaching vehicle, and reacts by flashing brighter and faster alerting both the bicyclist and oncoming traffic. The COBI connected bicycle system also delivers a taillight with collision avoidance technology and turn signals, and Ford's MoDe e-bike proposed vibrating handlebars that would notify the bicyclist of overtaking vehicles, which account for a notable portion of vehicle-bicycle collisions (McLeod and Murphy, 2014). A study by the League of American Bicyclists (2014) found that $40 \%$ of fatalities with reported collision types were rear-end collisions. These devices could greatly enhance the bicyclist's awareness, allowing them to adjust their position or behavior in a timely manner to prevent a collision. They also increase the visibility of the bicyclists, which is especially important at night when safety margins are often insufficient; bicyclist fatalities most commonly occur between the hours of 6 and 9 p.m. in low light conditions (U.S. DOT, 2017a). Hexagon and COBI and other connected bicycle devices such as Cosmo and Helios Bars also provide bicyclists with LED turn signals, which can be safer than conventional hand signals. 
Table 1 - Barriers to Cycling and Connected Applications

\begin{tabular}{|c|c|c|c|c|c|c|c|c|}
\hline \multicolumn{2}{|c|}{ Barriers } & \multicolumn{2}{|c|}{ Applications } & \multicolumn{3}{|c|}{ Communication } & \multicolumn{2}{|c|}{ Sensors } \\
\hline $\begin{array}{l}\text { Barrier } \\
\text { Classification }\end{array}$ & $\begin{array}{l}\text { Barrier } \\
\text { Specification }\end{array}$ & Applications & $\begin{array}{l}\text { U.S. DOT } \\
\text { Applications }\end{array}$ & DSRC & $\begin{array}{l}\text { Cellular } \\
\text { B2V }\end{array}$ & $\begin{array}{l}\text { Cellular } \\
\text { B2I }\end{array}$ & $\begin{array}{l}\text { Vehicle } \\
\text { Sensor }\end{array}$ & $\begin{array}{l}\text { Bicycle } \\
\text { Sensor }\end{array}$ \\
\hline \multirow{5}{*}{ Safety Barriers } & $\begin{array}{l}\text { Bicycle- } \\
\text { Vehicle } \\
\text { Collisions }\end{array}$ & $\begin{array}{l}\text { Approaching Vehicle } \\
\text { Detection and } \\
\text { Warning; Reactive } \\
\text { Bicycle Lighting and } \\
\text { Turn Signals; } \\
\text { Collision Detection } \\
\text { and Emergency } \\
\text { Contact }\end{array}$ & $\begin{array}{l}\text { Red Light Violation } \\
\text { Warning; Ped in } \\
\text { Signalized } \\
\text { Crosswalk; } \\
\text { Emergency Electronic } \\
\text { Brake Lights; } \\
\text { Forward Collision } \\
\text { Warning; Blind } \\
\text { Spot/Lane Change } \\
\text { Warning; Vehicle } \\
\text { Turning Right } \\
\text { Warning; Intersection } \\
\text { Movement Assist }\end{array}$ & Yes & Yes & Yes & Yes & Yes \\
\hline & $\begin{array}{l}\text { Mobile Phone } \\
\text { Distractions }\end{array}$ & $\begin{array}{l}\text { Turn-by-Turn } \\
\text { Navigation; Hands- } \\
\text { Free SMS and } \\
\text { Calling }\end{array}$ & & No & No & No & No & No \\
\hline & $\begin{array}{l}\text { Dangerous } \\
\text { Routes and } \\
\text { Intersections }\end{array}$ & $\begin{array}{l}\text { Reactive Bicycle } \\
\text { Lighting and Turn } \\
\text { Signals; Social } \\
\text { Networking }\end{array}$ & $\begin{array}{l}\text { Forward Collision } \\
\text { Warning; Advanced } \\
\text { Traveler Information } \\
\text { System }\end{array}$ & Yes & Yes & Yes & No & Yes \\
\hline & $\begin{array}{l}\text { Street/Path } \\
\text { Lighting }\end{array}$ & $\begin{array}{l}\text { Smart and Adaptive } \\
\text { Lighting }\end{array}$ & & Yes & No & Yes & No & Yes \\
\hline & $\begin{array}{l}\text { Bicyclist } \\
\text { Visibility }\end{array}$ & $\begin{array}{l}\text { Reactive Bicycle } \\
\text { lights and Turn } \\
\text { Signals }\end{array}$ & & Yes & Yes & No & No & Yes \\
\hline \multirow{3}{*}{$\begin{array}{l}\text { Physical } \\
\text { Barriers }\end{array}$} & $\begin{array}{l}\text { Physical } \\
\text { Health }\end{array}$ & $\begin{array}{l}\text { Electric Assist; } \\
\text { Route Preference; } \\
\text { Health Monitoring; } \\
\text { Collision Detection \& } \\
\text { Emergency Contact }\end{array}$ & & No & No & No & No & Yes \\
\hline & Topography & $\begin{array}{l}\text { Electric Assist; } \\
\text { Route Preferences }\end{array}$ & & No & No & No & No & Yes \\
\hline & Distance & $\begin{array}{l}\text { Electric Assist; } \\
\text { Route Preferences }\end{array}$ & & No & No & No & No & Yes \\
\hline \multirow{3}{*}{$\begin{array}{l}\text { Navigation/ } \\
\text { Mobility } \\
\text { Barriers }\end{array}$} & $\begin{array}{l}\text { Routing } \\
\text { Options }\end{array}$ & $\begin{array}{l}\text { Popular Routes; } \\
\text { Route Preferences; } \\
\text { Social Networking }\end{array}$ & $\begin{array}{l}\text { Advanced Traveler } \\
\text { Information System }\end{array}$ & No & No & No & No & No \\
\hline & $\begin{array}{l}\text { Route } \\
\text { Obstructions }\end{array}$ & $\begin{array}{l}\text { Pothole Detection; } \\
\text { Social Networking }\end{array}$ & $\begin{array}{l}\text { Forward Collision } \\
\text { Warning; Advanced } \\
\text { Traveler Information } \\
\text { System }\end{array}$ & Yes & Yes & Yes & Yes & Yes \\
\hline & $\begin{array}{l}\text { Mixed-Traffic } \\
\text { Intersections }\end{array}$ & & $\begin{array}{l}\text { Interaction Movement } \\
\text { Assist; Intelligent } \\
\text { Traffic Signal } \\
\text { Systems }\end{array}$ & Yes & Yes & Yes & Yes & Yes \\
\hline \multirow{4}{*}{$\begin{array}{l}\text { Additional } \\
\text { Barriers }\end{array}$} & $\begin{array}{l}\text { Bicycle } \\
\text { Security }\end{array}$ & $\begin{array}{l}\text { Lock, Alarm, \& } \\
\text { Track; Theft } \\
\text { Detection }\end{array}$ & & No & No & No & No & Yes \\
\hline & Children/Cargo & $\begin{array}{l}\text { Electric Assist; } \\
\text { Route Preferences }\end{array}$ & & No & No & No & No & Yes \\
\hline & $\begin{array}{l}\text { Bicycle } \\
\text { Community }\end{array}$ & $\begin{array}{l}\text { Performance } \\
\text { Monitoring; Social } \\
\text { Networking; Bicycle } \\
\text { Sharing }\end{array}$ & & No & No & No & No & Yes \\
\hline & $\begin{array}{l}\text { Mechanical } \\
\text { Issues }\end{array}$ & $\begin{array}{l}\text { Maintenance Status } \\
\text { and Repair } \\
\text { Prediction }\end{array}$ & & No & No & No & No & Yes \\
\hline
\end{tabular}


Numerous connected bicycle technologies can detect a crash utilizing data collected from an onboard accelerometer. When devices like the Ellipse smart lock, Garmin Edge, The BikeSpike, or Cosmo detect that a crash has occurred they send a message to the bicyclist's smartphone asking whether or not they wish to have an alert with their location sent to their emergency contacts; if the bicyclist does not respond in a given amount of time the alert will be sent. These devices can enhance the comfort of both the bicyclist and their friends and family members. Furthermore, connected bicycle technologies, such as ELEMNT, SmrtGrips, and COBI allow friends and family to track their loved ones while they bike.

Turn-by-turn navigation is another popular safety application. This feature can help reduce the risks associated with mobile phone distractions. Numerous connected devices can link to compatible navigation apps on the bicyclist's smartphone through Bluetooth connection and provide alerts of upcoming turns through haptic (SmrtGrips), visual (Beeline, Shoka Bell, and SmartHalo), and audio alerts (COBI and Sena X1). If the apps being utilized can effectively receive traffic updates and road condition information, the connected bicycle features can direct bicyclists away from potentially dangerous intersections and routes. Some apps and connected bicycle technologies rely on "local wisdom" where bicyclists can voluntarily report potholes and other undesirable conditions. Shoka Bell and SmrtGrips propose to use real-time traffic alerts and community-sourced information to assist bicyclists along the safest route while avoiding dangerous intersections. A few technologies, such as COBI and the Sena X1 helmet, offer the ability to make and answer phone calls without removing ones' hands from the handlebars. By avoiding potentially risky interactions with their smartphones, bicyclists can greatly enhance the safety conditions of their ride.

\subsubsection{Physical Applications}

Many individuals face physical limitations that may deter them from bicycling, such as health conditions, living in a hilly area, and living far from where they work and play. Studies have found that electric bicycles (e-bikes) can be useful for mitigating the effect of these barriers (MacArthur et al., 2017; Langford et al., 2013; Langford et al., 2017). E-bikes provide a unique opportunity to enhance the development of connected bicycles because they come equipped with a battery, which can serve as a platform for integrating sensor technologies and GPS. Companies such as Stromer, Vanmoof, and VisioBike have begun to take advantage of this opportunity. Each of these companies has developed an e-bike with integrated Bluetooth sensor technologies, which transmit data to other connected devices within the bicycle (i.e., dashboard, lights, motor, etc.), and/or compatible smartphone apps. These features and the crash detection technologies discussed above can be especially important for individuals facing health barriers by providing additional awareness to help avoid an incident or pedal assistance. 


\subsubsection{Navigation/Mobility Applications}

While navigation apps have been widely available for bicyclists, they are an integral part of the connected bicycle infrastructure and could greatly benefit from some of the advantages of connected bicycles. Many of the technologies which are compatible with popular navigation and tracking apps like Strava and Garmin Edge or provide a navigation interface through their own app offer features such as fastest route, shortest route, most popular route, safest route, and even quietest route (COBI, Cowboy). The latter three features can be derived from information voluntarily published within the bicycling community (i.e., route data, pothole location, previous collisions, etc.) and data collected from onboard sensors and shared to the internet (ground surface condition, ambient noise, etc.). These features are essential to increasing the total number of trips taken by bicycle because not knowing how long a trip will take or the quickest and safest way to get to a destination can be a significant deterrent for choosing to travel by bicycle; the data collected and shared regarding specific urban and suburban routes via connected bicycles can help to reduce the impact of this barrier.

Bicyclists are also sensitive to route obstructions which may impact the expected progress of a trip, such as congestion, roadwork/construction, and ground conditions which could cause damage to the bicycle or a crash (i.e., pothole, icy road, road debris, etc.). As stated earlier, the detection of these hazards is currently achieved through voluntary reporting to social media/navigation platforms. However, Ford claims that its MoDe e-bikes are capable of detecting upcoming road hazards and notifying the bicyclist with haptic alerts through the handlebars. Having this information allows a bicyclist to avoid potential hazards and reroute their trip to make good progress with fewer delays.

\subsubsection{Miscellaneous Applications}

The fear of having a bicycle stolen can be a significant deterrent for certain types of trips and/or trips to certain destinations. It could also discourage an individual from purchasing a bicycle. Brought-in and built-in connected bicycle technologies can significantly increase bicycle security. Bicycle-mounted devices such as Boomerang CycloTrac, Shoka Bell, and B.Guard utilize motion sensors to detect theft, and when suspicious movement is detected they activate an alarm and send an alert to the owner through a compatible app or SMS message. These and other devices are also equipped with GPS chips, allowing the owner to track their bicycle if the theft is not prevented. Smart locks such as Lock8 and Ellipse also utilize sensor technology to protect the bicycle from theft. Some smart bikes (Vanmoof X) and e-bikes (Stromer ST1 X, Vanmoof $S$, and Cowboy) come equipped with some or all of these features.

Studies have shown that the need to haul cargo and transport children can be a significant barrier to traveling by bicycle (MacArthur et al., 2017). Similar to the physical barriers, the electric assist of e-bikes could enhance the feasibility of bicycling for individuals who must carry additional weight they might not feel comfortable carrying on a standard bicycle, especially with connected features such as "No-Sweat Mode." 
Maintenance issues are another concern that may prevent (need a new tire) or discourage (fear of running out of battery) an individual from bicycling for a given trip. Stromer ST1 X, Bulls, and Cowboy connected e-bikes have the ability to provide realtime maintenance information about the bicycle. Providing information about the condition of the bicycle (tire pressure, battery level, brake wear) allows the bicyclist to assess the situation and take action before a mechanical failure occurs, which could disrupt a trip and/or jeopardize the integrity of the bicycle. While this feature was found only in connected e-bikes there is potential for the sensor technology to be integrated into any bicycle. Real-time maintenance information could be especially important for fleet operators such as bike share companies.

Measuring and tracking personal performance metrics has become an increasingly popular trend in the U.S. Smartphone apps like Strava have enabled bicyclists to track and share information about individual trips, such as route, speed, distance, and elevation. While this is possible without connected bicycle technologies, pairing tracking apps with a connected bicycle computer (ELEMNT and Garmin Edge), handlebarmounted device (SmartHalo and Beeline), and/or connected wearables (GPS watches and heart rate monitors) can improve the experience and enable users to track additional performance metrics (i.e., heart rate, calories burned, etc.). Tracking and sharing performance data facilitates goal-oriented riding and friendly competition, and can encourage individuals to ride further, harder, and more frequently (Weber et al., 2018). Friendly competitions such as Portland's Bike More Challenge are commonly used as a strategy to increase rates of bicycling. These devices also make it easier for individuals with varying health conditions to monitor important metrics, which could permit the prevention of a health-related incident while bicycling.

\subsection{TWO-WAY COMMUNICATION}

Dedicated Short Range Communications, the proposed technology behind V2X communications, allow equipped road users to transmit data (speed, heading, position) at low latency up to 10 times per second. These messages can be received by other equipped entities (e.g., other road users and infrastructure) within an approximate range of 300 meters. All equipped entities are continuously transmitting and receiving data via two-way communication modes (see Figure 5). The messages are used to detect potential dangers imposed by traffic, terrain, or weather and provide the user with appropriate warnings. Currently, these devices are most widely considered for their potential to reduce the risks of vehicle-to-vehicle collisions and V2I communication; however, as mobile DSRCs have become available (e.g., LocoMate ME) researchers have begun to assess their potential to enhance safety for bicyclists and pedestrians (Jenkins et al., 2016; Razzaque and Clarke, 2015; Anaya et al., 2014). Field tests have revealed numerous challenges, such as size, GPS limitations and battery drain caused by the intensive task of continuously transmitting, receiving, and interpreting data; however, they clearly demonstrate the progress being made towards integrating bicycles into the connected network. Researchers have also tested the potential of providing V2X/B2 V communication through integrated mobile devices utilizing $5 \mathrm{G}$ cellular connectivity (Diewald et al., 2015). Tome Software has partnered with Trek 
Bikes to develop a B2V communication system that relies on cellular connection (Tome, 2018). Figure 5 depicts a two-way communication environment.

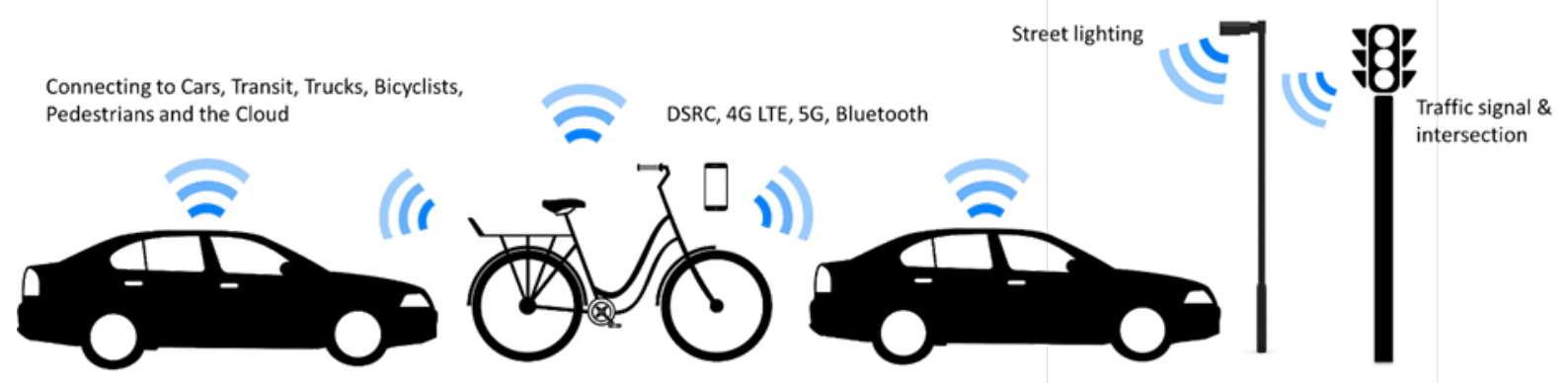

Figure 5 - Two-Way Communication Environment

The data generated through the process of two-way communication will help cities identify important traffic trends (e.g., collision hot spots, travel speeds, road user behavior, etc.) and support smart city initiatives. These data would contribute significantly to the information collected by existing technologies such as traffic monitoring sensors. NUMINA's streetlight-mounted sensors are able to differentiate between all types of traffic, including bicyclists, pedestrians and motorists, which enables the collection of important multimodal travel data (NUMINA, 2018). Below we will address the relevant applications of two-way communications and discuss how they address safety and mobility challenges faced by bicyclists.

\subsubsection{Safety Applications}

It should be expected that successful implementation of B2V and B2I communication networks would provide bicyclists with many of the same safety benefits projected for $\mathrm{CV}$ operators. Bicyclists would be able to alert other road users of their presence and receive warnings regarding potential collisions, dangerous intersections, encroaching vehicles, and road hazards and conditions (refer to Table 1 for the list of safety applications). The connection between bicyclists and other road users will provide the necessary road users (i.e., bicyclist, motorist, or both) with the appropriate alert, prompting them to take action to avoid a collision or dangerous situation. On the motor vehicle side of things, additional measures such as automatic breaking will provide further support. It should be expected that such significant enhancements in actual and perceived safety could result in increased levels of bicycle travel (Silla et al., 2016).

B2I connection could permit communication between bicyclists and equipped streetlights, traffic signals, roadside units, and surface infrastructure. B2I technologies could reduce the number of right-hook accidents caused by motorists, support smart and adaptive lighting and signal prioritization applications, and provide bicyclists with red-light violation warnings. Intelligent transportation infrastructure would be able to recognize dangerous driving behavior and notify nearby bicyclists so they can take the appropriate actions to avoid a potentially dangerous situation. Equipped street and path lights could recognize approaching bicycles and enhance visibility in low-light 
conditions, which could be especially vital to individuals residing in areas where crime may be a more significant barrier to bicycling. These connected bicycle applications would greatly improve situational awareness and reduce the likelihood of vehicle-bicycle collisions, which could encourage less confident bicyclists to ride.

\subsubsection{Navigation/Mobility Applications}

Certain connected applications could also enhance the traveling experience for bicyclists. Advanced Traveler Information Systems could provide bicyclists with realtime information regarding collisions, weather, recommended speeds, and road conditions. This information could be used to generate optimal routes and to avoid potentially dangerous intersections or roadways. Furthermore, B2I communication would permit signal prioritization for cyclists; the ability of Intelligent Traffic Signal Systems to recognize and prioritize bicyclists could greatly reduce the number of stops and starts required on a given trip. Currently, relevant research efforts are focused on V2I communication utilizing DSRC; however, technology companies have explored utilizing Bluetooth integrated infrastructure to communicate with nearby smartphones through an interface provided by a compatible app (DEVPOST, 2018). Similarly, the Tampa Connected Vehicle Pilot introduced a smartphone app, which allows pedestrians and bicyclists to request a "walk" signal at select intersections (Tampa Hillsborough Expressway Authority, 2018). Successful B2I communication could improve travel time and reduce physical effort required for a bicycle trip by reducing the frequency of stops. These two factors can be significant deterrents to bicycling, especially for commute purposes. 


\subsection{LIMITATIONS AND BENEFITS}

When compared, each connected bicycle environment has a unique set of limitations and benefits. However, there are some limitations that they share, which are inherent in the mass distribution of data and reliance on various technological components (i.e., modules, sensors, connection modes). Cybersecurity and remote hacking are amongst the more significant challenges and fears associated with CV and bicycles; an international consumer survey found that 34\% of vehicle owners currently do not trust either automakers or technology companies with their in-car data and privacy (Cookson and Pishue, 2017). With no fullproof way to protect DSRCs or other devices from being accessed remotely, attackers could manipulate data and share falsified information. Travel data and personal information could also be collected and abused by attackers.

GPS capabilities have also proven to be a significant challenge for both cellular C-V2X and mobile DSRC communications; GPS coordinates can easily be distorted due to a blockage of signal by physical barriers such as tall buildings or trees (Jenkins et al., 2016; Tironi and Valderrama, 2017). This can adversely impact the functionality of situational sensing devices and two-way communication systems. The primary GPS concerns for situational sensing devices include the possibility for thieves to block the bicycles GPS signal; providing inaccurate location data in the case of a detected collision; and producing inaccurate route data. With two-way communications the risks could be more substantial; inaccurate coordinates could generate false warnings in harmless situations or no warnings in potentially dangerous situations (Gubbi et al., 2012). Another common concern for connected technologies is the issue of interoperability; different systems must be able to exchange and make use of the information gathered in order to be successful. This concern is exemplified by Volvo's smart-helmet prototype which would permit two-way communication between bicyclists and Volvo drivers through the Volvo Cloud. Utilizing a restricted cloud-based safety system significantly reduces the potential effect of the system. Among other benefits, the widespread use of DSRCs could provide interoperability.

The primary benefit of situational sensing devices is that their utility is not entirely dependent on the number of users within the network (network effect). While in some cases the benefits would increase with more equipped users, the devices can function in the absence of other connected devices. On the other hand, two-way communication cannot be achieved if surrounding road users are not connected, and even with the passing of the federal DSRC mandate this could take decades to achieve. However, in the case where all road users are connected, the actual safety and mobility benefits will likely be much greater than those provided by devices, which only alert the bicyclist or driver. Having collision prediction alerts sent to the vehicle could also permit the use of emergency braking services, which would enhance the safety margins for bicyclists. Only a few situational sensing devices make any attempt at communicating with surrounding road users, and the communication capabilities of those that do are limited. For example, the See.Sense Icon taillight reacts to its environment and flashes brighter 
and faster in dangerous situations, which requires the driver to acknowledge and understand the message behind the signal.

It is expected that B2V communication in congested urban areas will result in an overabundance of warning messages sent to drivers and bicyclists, regardless of whether there is imminent danger. Researchers claim that a high quantity of messages, spurious or real, will cause annoyance and lead to moderate to high non-usage rates and disregard for the warnings (Silla et al., 2016). Furthermore, these warnings could distract road users and lead to crashes; Tome attempts to address this issue by utilizing a system, which sends alerts to the driver rather than the bicyclist. Another projected limitation of two-way communication is the potential of overreliance on the system; a survey of Oregon Department of Transportation employees demonstrated that there is significant concern regarding driver overreliance (Bertini et al., 2016). Silla et al. (2016) expect drivers will become less cautious due to presumptions that the system will alert or aid them in case of a potential incident.

While improving safety and mobility measures tend to be the central focus of the CV and B2V dialog, it is important not to disregard the additional benefits provided by connected bicycle technologies. Innovations in situational sensing devices has enabled theft detection and GPS tracking, adaptive electric assist for e-bikes, simplified smartphone interaction, innovative use of social networks, and increased awareness of maintenance requirements. These applications do not necessarily pertain to B2V communication, yet they can significantly enhance the riding experience and make bicycling a more competitive transportation option. It is evident that there are numerous benefits tied to the advancement of these technologies, yet certain challenges and limitations, internal and external, may hinder their effectiveness. 


\subsection{DISCUSSION}

The question of whether bicycles simply detect vehicles and infrastructure (or vice versa) or there will be direct communication between them is fundamental to the future of a connected transportation network. Currently, the readily available technologies seem to support the former option; both automakers and bicycle manufacturers provide sensor technologies that permit the detection of other road users. For example, some new vehicles come equipped with blind spot detection and pedestrian and bicyclist detection technologies that alert the driver and can enable emergency braking services, and connected bicycle devices such as the Garmin Varia can detect and alert the bicyclist of encroaching vehicles. While very few vehicles are currently sold equipped with DSRCs, there is tremendous federal and private support for CV technology. Caution needs to be considered to when developing and rolling out the technology to make sure users and drivers don't become over-reliant in the technology. It will take many years before a connected environment is fully-developed that includes all users.

The U.S. DOT Connected Vehicle Pilot Program has initiated projects with New York City, Tampa, and Wyoming to support the deployment of CV technology (U.S. DOT, 2018d). While the projects primarily focus on enabling V2V and V2I communication to support CV applications, both the NYC and Tampa projects include a vehicle-topedestrian (V2P) component. The $\mathrm{V} 2 \mathrm{P}$ technologies provide equipped infrastructure with the abilities to warn vehicles of pedestrians and bicyclists within the crosswalk of an upcoming intersection, allow pedestrians and bicyclists to request a "walk" signal at select intersections (Tampa), and enhance intersection mobility for disabled and visually impaired pedestrians. For the latter application, NYC assumes this will be achieved utilizing a portable personal information device (PID) which operates as a cellular device and communicates in the DSRC spectrum (NYC DOT, 2016).

Although there is no direct communication between the pedestrian or bicyclist and the vehicle (i.e., pedestrians/bicyclists are detected by a roadside unit that alerts nearby vehicles), the technologies demonstrate the feasibility of connectivity for non-motorists utilizing mobile devices (e.g., smartphone app and mobile DSRC). Similar technology could be used to provide signal prioritization for bicyclists and direct B2V

communications; this does not appear to be central to the current U.S. DOT CV mission but could lead to conceptual and technological advancements, which support and enable direct communication with vulnerable road users.

As sensor technologies continue to improve and prices decline, they will likely become more widely used and available. A high adoption rate of these devices could significantly enhance road safety and reduce collisions for bicyclists. It is our contention that the benefits of situational sensing devices will eventually be supported and enhanced by two-way communication. Two-way communications will not render situational sensing devices obsolete, because many of them support applications that are not supported by direct communication between other road users and infrastructure. However, they will enhance the safety benefits by enabling greater awareness of the 
surrounding environment and better address bicyclists' mobility needs by permitting signal prioritization and advanced traveler information systems. 


\subsection{CONCLUSION}

As the societal benefits of active travel come to fruition in the U.S., cities seek to encourage bicycling by addressing the specific barriers and needs of the mode's diverse users. Advocates, academics, and practitioners often focus on the impacts of infrastructure, policies and programs, and access, yet technology tends to be ignored as a critical component of increasing bicycling rates. In this paper, we examined the existing and projected applications of connected bicycle technologies and explored the ways in which they could address some of the barriers to bicycling. Table 1 provided a list of these applications, some of which were pulled from the U.S. DOT's connected vehicle applications and the others were developed after reviewing the capabilities of existing connected bicycle technologies. The information in Table 1 links each barrier to the appropriate applications and considers the communication type and sensor technology, which provides a framework for future development and discussion around connected bicycles.

In conducting this research, it has become evident that there is a lack of consideration of bicyclists in the U.S. DOT's, state DOTs', and local DOTs' CV initiatives. The U.S. DOT has spent over five years developing more than three dozen CV applications, yet none of them directly acknowledge the presence of bicyclists on the road. As a result, there is limited mention of bicyclists in both the New York City and Tampa Connected Vehicle Pilot Programs. In these projects, bicyclists take the same role as pedestrians in that their presence is recognized by pedestrian detection technologies and they can request a "walk" signal utilizing a smartphone app at select intersections. However, it is projected that many of the CV applications could benefit bicyclists in the same way they do motorists. We believe that bicycle manufacturing companies, bicycle advocates, and active transportation planners should be included in the connected vehicle conversations taking place at all scales of government. As connected technologies advance, these groups have a unique opportunity to explore new concepts and encourage the integration of connected bicycles.

If bicycling is not considered a competitive transportation option within communities, it is unlikely that the mode share will increase. Governments are often looked upon to address this challenge; however, private actors such as bicycle manufacturers and technology companies also play an integral role. 


\subsection{REFERENCES}

5G Americas. Cellular V2X Communications Towards 5G. Seattle, WA, 2017. http://www.5gamericas.org/en/resources/white-papers/

Anaya, J.J., P. Merdrignac, O. Shagdar, F. Nashashibi, and J. E. Naranjo. "Vehicle to pedestrian communications for protection of vulnerable road users." Intelligent Vehicles Symposium Proceedings, IEEE, 2014. 1037-1042.

ASCE. "Funding \& Future Need." ASCE's 2017 Infrastructure Report Card. https://www.infrastructurereportcard.org/roads/funding-future-need/ Accessed May 10, 2018.

Aytur, S., D. Rodriguez, K. Evenson, D. Catellier, and W. Rosamond. "The sociodemographics of land use planning: relationships to physical activity, accessibility, and equity." Health \& Place, 2008. 14, no. 3: 367-385.

Bertini, Robert, Haizhong Wang, Tony Knudson, and Kevin Carstens. "Preparing a roadmap for connected vehicle/cooperative systems deployment scenarios: Case study of the state of Oregon, USA." Transportation Research Procedia, 2016. 15: 447-458.

Boarnet, M., C. Anderson, K. Day, T. McMillan, and M. Alfonzo. "Evaluation of the California Safe Routes to School legislation: urban form changes and children's active transportation to school." American Journal of Preventive Medicine, 2005. 28, no. 2: 134-140.

Buehler, R., and J. Dill. "Bikeway networks: A review of effects on cycling." Transport Reviews, 2016. 36, no. 1: 9-27.

Buehler, R., and J. Pucher. "Cycling to work in 90 large American cities: new evidence on the role of bike paths and lanes." Transportation, 2012. 39, no. 2: 409-432.

Calem, R. "What happens when 5G combines With Vehicles?" Consumer Technology Association, 2017. https://www.cta.tech/News/i3/Articles/2017/SeptemberOctober/What-Happens-When-5G-Combines-With-Vehicles.aspx.

Clifton, Kelly, Kristina M. Currans, Christopher D. Muhs, Chloe Ritter, Sara Morrissey, and Collin Roughton. "Consumer Behavior and Travel Choices: A Focus on Cyclists and Pedestrians." In 92nd Annual Meeting of the Transportation Research Board. Washington, DC, Vol. 14, 2012.

Cookson, G. and B. Pishue. "INRIX Connected \& Autonomous Vehicle Consumer Survey." INRIX Research, 2017.

Cookson, Graham. “INRIX Global Traffic Scoreboard.” INRIX Research, 2018. 
Cooper, Carol. "Successfully changing individual travel behavior: Applying communitybased social marketing to travel choice." Transportation Research Record: Journal of the Transportation Research Board, 2007. 2021: 89-99.

DEVPOST. "Connected Intersections - Tug." https://intersections.devpost.com/submissions/26533-tug Accessed June 1, 2018.

Diewald, S., T. Leinmüller, B. Atanassow, L. Breyer, and M. Kranz. "Mobile Device Integration and Interaction with V2X Communication." World Congress on Intelligent Transport Systems, 2012. 22/10/2012-26/10/2012.

Dill, J. and N. McNeil. "Revisiting the four types of cyclists: findings from a national survey." Transportation Research Record: Journal of the Transportation Research Board, 2016. 2587: 90-99.

Dill, J. and T. Carr. "Bicycle Commuting and Facilities in Major US Cities: If You Build Them, Commuters Will Use Them." Transportation Research Record: Journal of the Transportation Research Board, 2003. 1828: 116-123.

Dill, J., S. Handy, and J. Pucher. "How to Increase Bicycling for Daily Travel. A Research Brief." Princeton, NJ: Active Living Research, a National Program of the Robert Wood Johnson Foundation; May 2013. https://activelivingresearch.org/howincrease-bicycling-daily-travel

Dill, Jennifer, and Kim Voros. "Factors affecting bicycling demand: initial survey findings from the Portland, Oregon, region." Transportation Research Record: Journal of the Transportation Research Board, 2007. 2031: 9-17.

Ewing, R., K. Bartholomew, S. Winkelman, J. Walters, D. Chen, B. McCann, and D. Goldberg. "Growing cooler: the evidence on urban development and climate change." Urban Land Institute, 2007. 814.

Frank, L. D. "Land Use and Transportation Interaction: Implications on Public Health and Quality of Life." Journal of Planning, Education, and Research, 2000. 20(1), 622.

Furth, G. P. "Bicycling Infrastructure for Mass Cycling: A Transatlantic Comparison." In City Cycling (J. Pucher and R. Buehler eds.), The MIT Press, Cambridge, MA, 2012. pp. 105-140.

Garrett-Peltier, Heidi. "Pedestrian and bicycle infrastructure: A national study of employment impacts." Amherst, MA: Political Economy Research Institute (2011).

Golub, Aaron, Richard A. Marcantonio, and Thomas W. Sanchez. "Race, space, and struggles for mobility: Transportation impacts on African Americans in Oakland and the East Bay." Urban Geography, 2013. 34, no. 5: 699-728. 
Gubbi, J., R. Buyya, S. Marusic, and M. Palaniswami. "Internet of Things (IoT): A vision, architectural elements, and future directions." Future generation computer systems, 2013. 29, no. 7: 1645-1660.

Handy, S., B. Van Wee, and M. Kroesen. "Promoting cycling for transport: research needs and challenges." Transport reviews, 2014. 34, no. 1: 4-24.

Heinen, E., B. Van Wee, and K. Maat, "Commuting by bicycle: an overview of the literature." Transport Review, 2010. 30, 59-96.

Hunter, W., J. Stutts, W. Pein, and C. Cox. "Pedestrian and Bicycle Crash types of the Early 1990's." FHWA-RD-95-163. 1996.

Jenkins, M., D. Duggan, and A. Negri. "Towards a connected bicycle to communicate with vehicles and infrastructure: Multimodel alerting interface with Networked ShortRange Transmissions (MAIN-ST)." In Cognitive and Computational Aspects of Situation Management (CogSIMA), IEEE Conference, 2017. pp. 1-3.

Johnson, M., Newstead, S., Charlton, J., and J. Oxley. (2011). "Riding Through Red Lights: The Rate, Characteristics and Risk Factors of Non-Compliant Urban Commuter Cyclists." Accident Analysis and Prevention, Vol. 43, Issue 1, pp. 323328.

Johnson, M., Newstead, S., Charlton, J., and J. Oxley. (2013). Why do Cyclists Infringe at Red Lights? An Investigation of Australian Cyclists' Reasons for Red Light Infringement." Accident Analysis and Prevention, Vol. 50, pp. 840-847.

Klein, L., Mills, M., and D. Gibson. Traffic Detector Handbook. Third Edition, Volume 1, 2006.

Langford, B., C. Cherry, D. Bassett Jr, E. Fitzhugh, and N. Dhakal. "Comparing physical activity of pedal-assist electric bikes with walking and conventional bicycles." Journal of Transport \& Health, 2017. 6: 463-473.

Langford, B., C. Cherry, T. Yoon, S. Worley, and D. Smith. "North America's first EBikeshare: a year of experience." Transportation Research Record: Journal of the Transportation Research Board, 2017. 2387: 120-128.

League of American Bicyclists. "Where We Ride Analysis of Bicycle Commuting in American Cities." The League of American Bicyclists, 2016. http://bikeleague.org/sites/default/files/LAB_Where_We_Ride_2016.pdf

Litman, Todd. "Evaluating active transport benefits and costs: guide to valuing walking and cycling improvements and encouragement programs." Victoria Transport Policy Institute (2017). 
Lovejoy, K. and S. Handy. "Developments in Bicycle Equipment and Its Role in Promoting Cycling as a Travel Mode." In City Cycling (J. Pucher and R. Buehler eds.), The MIT Press, Cambridge, MA, 2012. pp. 75-104.

Lu, N., N. Cheng, N. Zhang, X. Shen, and J. Mark. "Connected vehicles: Solutions and challenges." IEEE Internet of Things Journal, 2014. 1, no. 4: 289-299.

Lyons, W., B. Rasmussen, D. Daddio, J. Fijalkowski, and E. Simmons. "Nonmotorized Transportation Pilot Program." Final Report. Washington, D.C.: U.S. Department of Transportation, May 2014.

MacArthur, J., C. Cherry, M. Harpool and D. Scheppke. A North American Survey of Electric Bicycle Owners. NITC-RR-1041. Portland, OR: Transportation Research and Education Center (TREC), 2018.

MacArthur, J., N. Kobel, J. Dill, and Z. Mumuni. Evaluation of an Electric Bike Pilot Project at Three Employment Campuses in Portland, OR. NITC-RR-564B. Portland, OR: Transportation Research and Education Center (TREC), 2017.

Marshall, Wesley E., and Norman W. Garrick. "Evidence on why bike-friendly cities are safer for all road users." Environmental Practice, 2011. 13, no. 1: 16-27.

McLeod, K. and L. Murphy. "Every Bicyclist Counts." The League of American Bicyclists, 2014.

Moudon, Anne Vernez, Chanam Lee, Allen D. Cheadle, Cheza W. Collier, Donna Johnson, Thomas L. Schmid, and Robert D. Weather. "Cycling and the built environment, a US perspective." Transportation Research Part D: Transport and Environment 10, no. 3 (2005): 245-261.

NHTSA. "Traffic Safety Facts: Race and Ethnicity, 2006 Data." NHTSA's National Center for Statistics and Analysis (2009).

NUMINA. "Real-time insights from streets." http://www.numina.co/ Accessed June 5, 2018.

NYC DOT. "Connected Vehicle Pilot Deployment Program Phase 1, Concept of Operations (ConOps) - New York City." New York City Department of Transportation, 2016.

Piramuthu, O. "Connected bicycles." International Conference on Future Network Systems and Security, 2016. pp. 172-186.

Piramuthu, O. "Connected Bicycles-State-of-the-Art and Adoption Decision." IEEE Internet of Things Journal, 2017. 4, no. 4: 987-995.

Pucher, J., and R. Buehler. "Walking and cycling for healthy cities." Built Environment, 2010. 36, no. 4: 391-414. 
Pucher, J., J. Dill, and S. Handy. "Infrastructure, programs, and policies to increase bicycling: an international review." Preventive medicine, 2010. 50: S106-S125.

Pucher, J., R. Buehler, D. Bassett, and A. Dannenberg. "Walking and cycling to health: a comparative analysis of city, state, and international data." American Journal of Public Health, 2010b. 100, no. 10: 1986-1992.

Razzaque, M., and S. Clarke. "A security-aware safety management framework for loTintegrated bikes." Internet of Things (WF-IOT), 2015 IEEE 2nd World Forum, 2015. pp. 92-97.

Rogers, Shannon H., John M. Halstead, Kevin H. Gardner, and Cynthia H. Carlson. "Examining walkability and social capital as indicators of quality of life at the municipal and neighborhood scales." Applied Research in Quality of Life, 2011. 6, no. 2: 201-213.

Rose, G., and H. Marfurt. "Travel behaviour change impacts of a major ride to work day event." Transportation Research Part A: Policy and Practice, 2007. 41, no. 4: 351364.

Sallis, J., L. Frank, B. Saelens, and M. K. Kraft. "Active transportation and physical activity: opportunities for collaboration on transportation and public health research." Transportation Research Part A: Policy and Practice, 2004. 38, no. 4: 249-268.

Sallis, J., T. Conway, L. Dillon, L. Frank, M. Adams, K. Cain, and B. Saelens. "Environmental and demographic correlates of bicycling." Preventive medicine, 2013. 57, no. 5: 456-460.

Savan, B., E. Cohlmeyer, and T. Ledsham. "Integrated strategies to accelerate the adoption of cycling for transportation." Transportation Research Part F: Traffic Psychology and Behaviour, 2017. 46: 236-249.

Seattle Department of Transportation (SDOT). City of Seattle Bicycle and Pedestrian Safety Analysis, 2016.

http://www.seattle.gov/Documents/Departments/beSuperSafe/BicyclePedestrianSaf etyAnalysis.pdf

Schneider, R.J. and J. Stefanich. Application of the Location-Movement Classfication Method for Pedestrian and Bicycle Crash Typing. Transportation Research Record: Journal of the Transportation Research Board. (2016) 2601, 72-83.

Silla, A., L. Leden, P. Rämä, J. Scholliers, M. Van Noort, and D. Bell. "Can cyclist safety be improved with intelligent transport systems?." Accident Analysis \& Prevention, 2017. 105: 134-145.

Smith, Oliver. "Commute Well-Being Differences by Mode: Evidence from Portland, Oregon, USA." Journal of Transport \& Health, 2016. 4: 246-54. 
Tampa Hillsborough Expressway Authority. "Get Involved, Pedestrians." Connected Vehicle Pilot. https://www.tampacvpilot.com/get-involved/pedestrian/ Accessed June 1, 2018.

Tironi, M., and M. Valderrama. "Unpacking a citizen self-tracking device: Smartness and idiocy in the accumulation of cycling mobility data." Environment and Planning D: Society and Space, 2018. 36, no. 2: 294-312.

Tome. "A perfect road match: bicycle to vehicle." https://www.tomesoftware.com/b2v/ Accessed June, 12018.

U.S DOT. "Connected Vehicle Pilot Deployment Program." https://www.its.dot.gov/pilots/ Accessed June 1, 2018.

U.S. DOT Vehicle-to-Pedestrian Research (White Paper). 2017b. FHWA-JPO-17-505

U.S. DOT. "Connected Vehicle Applications." 2018a. https://www.its.dot.gov/pilots/cv_pilot_apps.htm Accessed June 1, 2018.

U.S. DOT. "Connected Vehicle Pilot Documents Boost CV Deployment Worldwide." https://www.its.dot.gov/pilots/cv_pilot_worldwide.htm Accessed June 1, 2018c.

U.S. DOT. "Household Spending on Transportation." https://www.bts.gov/browse-statisticalproducts-and-data/transportation-economic-trends/tet-2017-chapter-6-household Bureau of Transportation Statistics (2017d)

U.S. DOT. "Traffic Safety Facts, Bicyclists and Other Cyclists, 2015 Data." NHTSA's National Center for Statistics and Analysis, 2017a.

U.S. DOT. "Traffic Safety Facts, Pedestrians, 2015 Data." NHTSA's National Center for Statistics and Analysis, 2017b.

U.S. DOT. "What Are Connected Vehicles and Why Do We Need Them?" https://www.its.dot.gov/cv_basics/cv_basics_what.htm Accessed June 1, 2018.

U.S. DOT. Connected Vehicles: Vehicle-to-Pedestrian Communications, 2017c. https://www.its.dot.gov/factsheets/pdf/cv_v2pcomms.pdf. Accessed June 1, 2018.

U.S. EPA. "Sources of Greenhouse Gas Emissions." https://www.epa.gov/ghgemissions/sources-greenhouse-gas-emissions Accessed June 1, 2018.

VTPI. "Walking and Cycling Encouragement: Strategies that Encourage People to Use Non-motorized Transportation." Victoria Transport Policy Institute: TDM Encyclopedia. http://www.vtpi.org/tdm/tdm3.htm Accessed June 1, 2018.

Watson, L. and M. Cameron. (2009). "Bicycle and Motor Vehicle Crash Characteristics." Final Report. Accident Research Center, Monash University. 
Weber, J., M. Azad, W. Riggs, \& C. Cherry. The convergence of smartphone apps, gamification and competition to increase cycling. Transportation Research Part F, 2018, 56: 333-343.

Winters, Meghan, Gavin Davidson, Diana Kao, and Kay Teschke. "Motivators and deterrents of bicycling: comparing influences on decisions to ride." Transportation, 2011. 38, no. 1: 153-168. 